\title{
Three Good Things
}

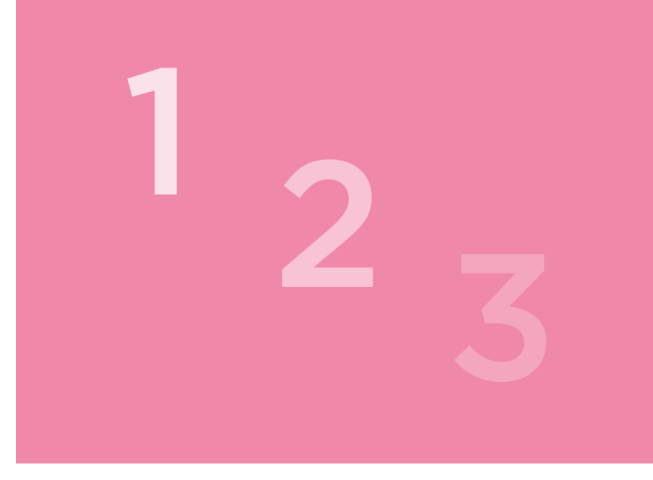

PAGE 1: Overview

PAGE 2: Activity

PAGE 3: Example

\section{How long does it take?}

10 minutes

\section{How do I do it?}

In this daily reflection, you list three things that went well for you, and why they went well.

\section{How does it work?}

This brief exercise helps you reflect on the many things that happen every day. Over time, you begin to look for things in your day to add to your list!

Inspired by: Seligman, M. E. P., Steen, T. A., Park, N., \& Peterson, C. (2005). Positive psychology progress: Empirical validation of interventions. American Psychologist, 60(5), 410-421. 


\section{Three Good Things}

\section{Character LAB}

At the end of each day, write down three things that went well for you and why they went well.

DATE

1

2

3

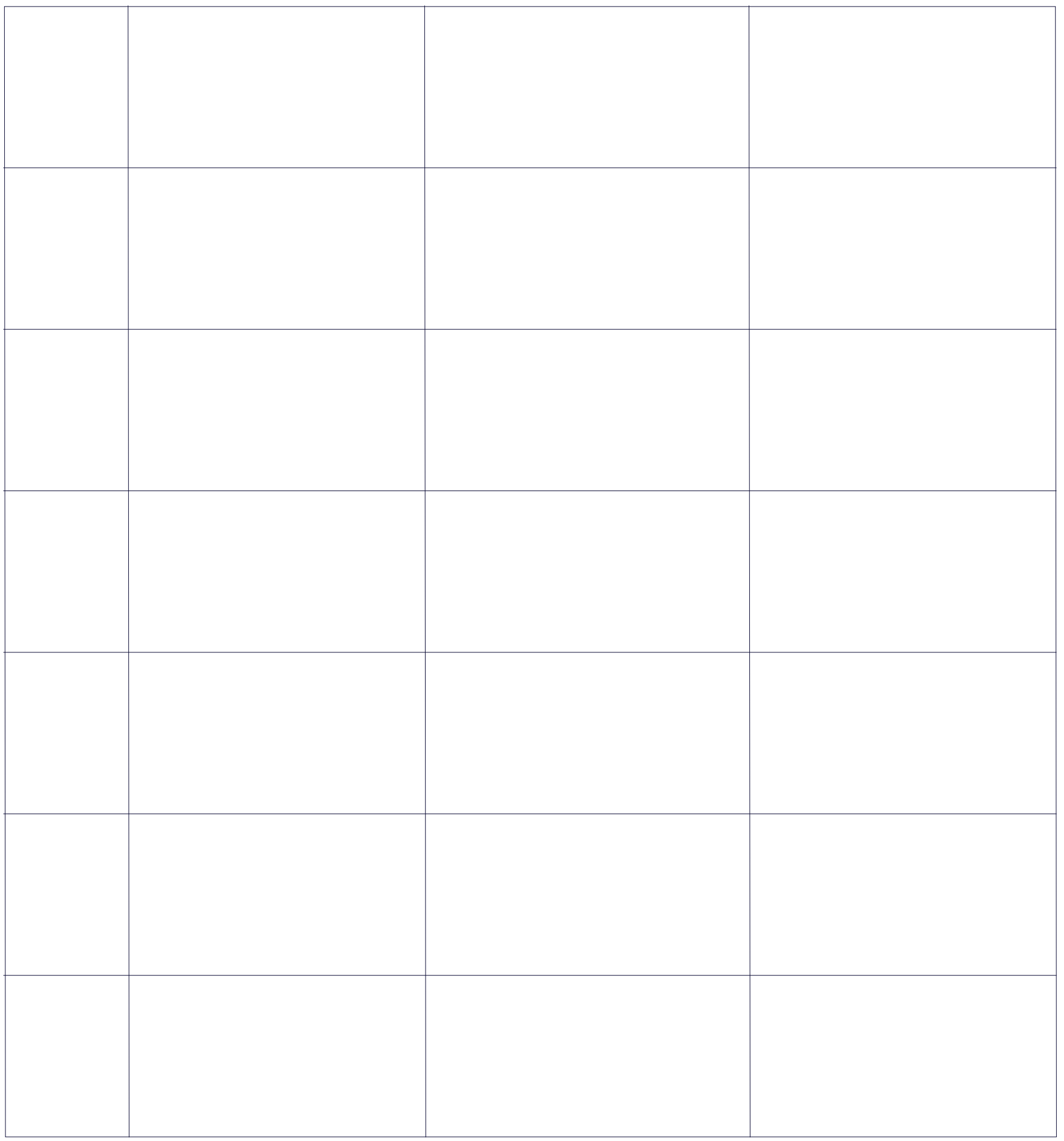




\section{Three Good Things}

\section{Character LAB}

\section{EXAMPLE}

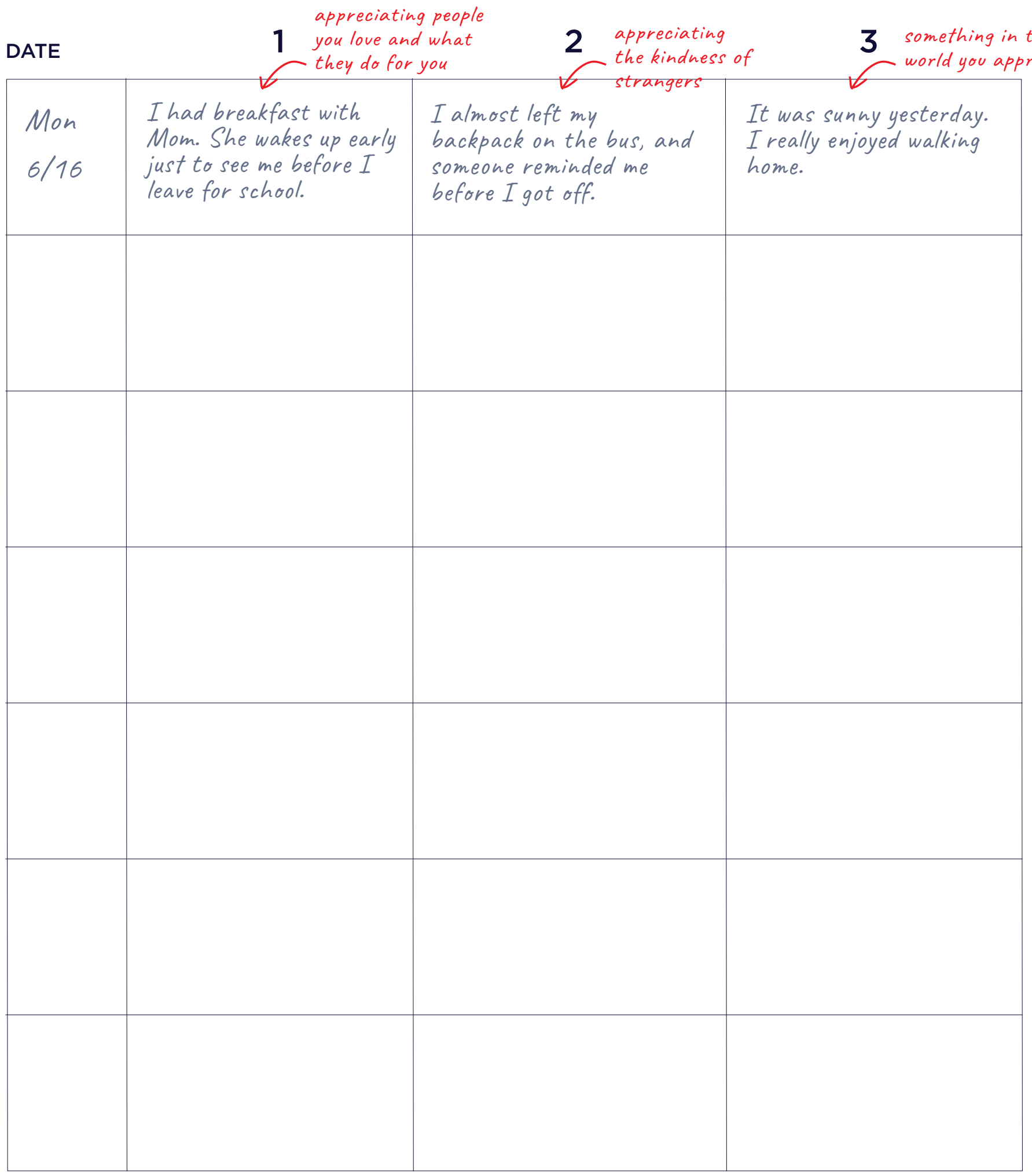

